Misselwitz Benjamin (Orcid ID: 0000-0002-8719-5175)

\title{
The oxysterol receptor GPR183 in inflammatory bowel diseases
}

Benjamin Misselwitz ${ }^{1)}$, Annika Wyss ${ }^{2)}$, Tina Raselli' ${ }^{2)}$, Vuc Cerovic ${ }^{3)}$, Andreas W. Sailer ${ }^{4)}$, Niklas Krupka ${ }^{1}$, Florian Ruiz ${ }^{5)}$, Caroline Pot $^{5)}$, Oliver Pabst ${ }^{3)}$

1) Gastroenterology, University Hospital of Visceral Surgery and Medicine, Inselspital Bern and Bern University, Switzerland

2) Department of Gastroenterology and Hepatology, University Hospital Zurich, University of Zurich, Switzerland

3) Institute of Molecular Medicine, RWTH Aachen University, 52074 Aachen, Germany

4) Disease Area X, Novartis Institutes for BioMedical Research, 4002 Basel, Switzerland

5) Laboratories of Neuroimmunology, Neuroscience Research Center and Division of Neurology, Department of Clinical Neuroscience, Lausanne University Hospital and University of Lausanne, Switzerland.

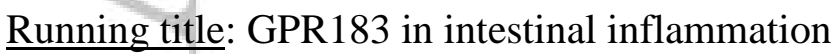

Key words: GPR183, EBI2, UBAC2, oxysterols, inflammatory bowel diseases, innate lymphoid cells, solitary intestinal lymphoid tissue, colitis

\section{Corresponding author:}

Benjamin Misselwitz, Gastroenterology, University Hospital of Visceral Surgery and Medicine, Inselspital Bern and Bern University, Freiburgstr. 18, 3010 Bern, Switzerland benjamin.misselwitz@insel.ch

\section{Disclosures:}

BM has served at an advisory board for Gilead and Novigenix. He has received speaking fees from Vifor, MSD and Takeda and traveling fees from Vifor, Novartis, Gilead, MSD and Takeda. BM has received a research grant from MSD unrelated to this work.

- AW is currently an Abbvie employee.

- TR has been a Takeda employee and is currently employed by Gilead.

- AWS is a Novartis employee and holds stocks and stock options in this company.

- CP has participated in advisory boards for Biogen, Celgene, Merck, Novartis and Roche unrelated to this work

- NK, VC, FR and OP have nothing to disclose

Funding statement: The authors did not receive funding for this study. This work was supported by grants from the Swiss National Science Foundation to BM (grant No. 32473B_156525). O.P. was supported by the German Research Foundation (DFG) Project-ID 403224013 - SFB 1382 (B06)

This article has been accepted for publication and undergone full peer review but has not been through the copyediting, typesetting, pagination and proofreading process which may lead to differences between this version and the Version of Record. Please cite this article as doi: 10.1111/bph.15311 
Author's contribution: BM did the literature research and prepared the figures. BM and OP wrote the paper. AWS, TR, AS, NK, FR, CP, VC and OP contributed to the interpretation of data and critically revised the manuscript and all figures for important intellectual content. All authors read and approved the final version of the manuscript. BM is the guarantor of this article.

\section{Abstract \\ Immune cell trafficking is an important mechanism for the pathogenesis of inflammatory bowel disease (IBD). The G-protein-coupled receptor 183 (GPR183, also called EBI2) and its ligands, dihydroxylated oxysterols can mediate positioning of immune cells including innate lymphoid cells (ILCs). GPR183 has been mapped to an IBD risk locus; however, another gene, UBAC2, is encoded on the reverse strand and associated with Behçet's disease and the role of GPR183 as a genetic risk factor requires validation.}

GPR183 and production of its oxysterol ligands are upregulated in human IBD and murine colitis. Gpr183 inactivation reduced severity of colitis in ILC3-dependent colitis and in IL-10 colitis but not in dextran sodium sulphate colitis. Irrespectively, Gprl83 knockout strongly reduced accumulation of intestinal lymphoid tissue in health and all colitis models.

In conclusion, genetic, translational and experimental studies implicate GPR183 in IBD pathogenesis and GPR183-dependent cell migration might be a therapeutic drug target for IBD. 


\section{List of abbreviations}

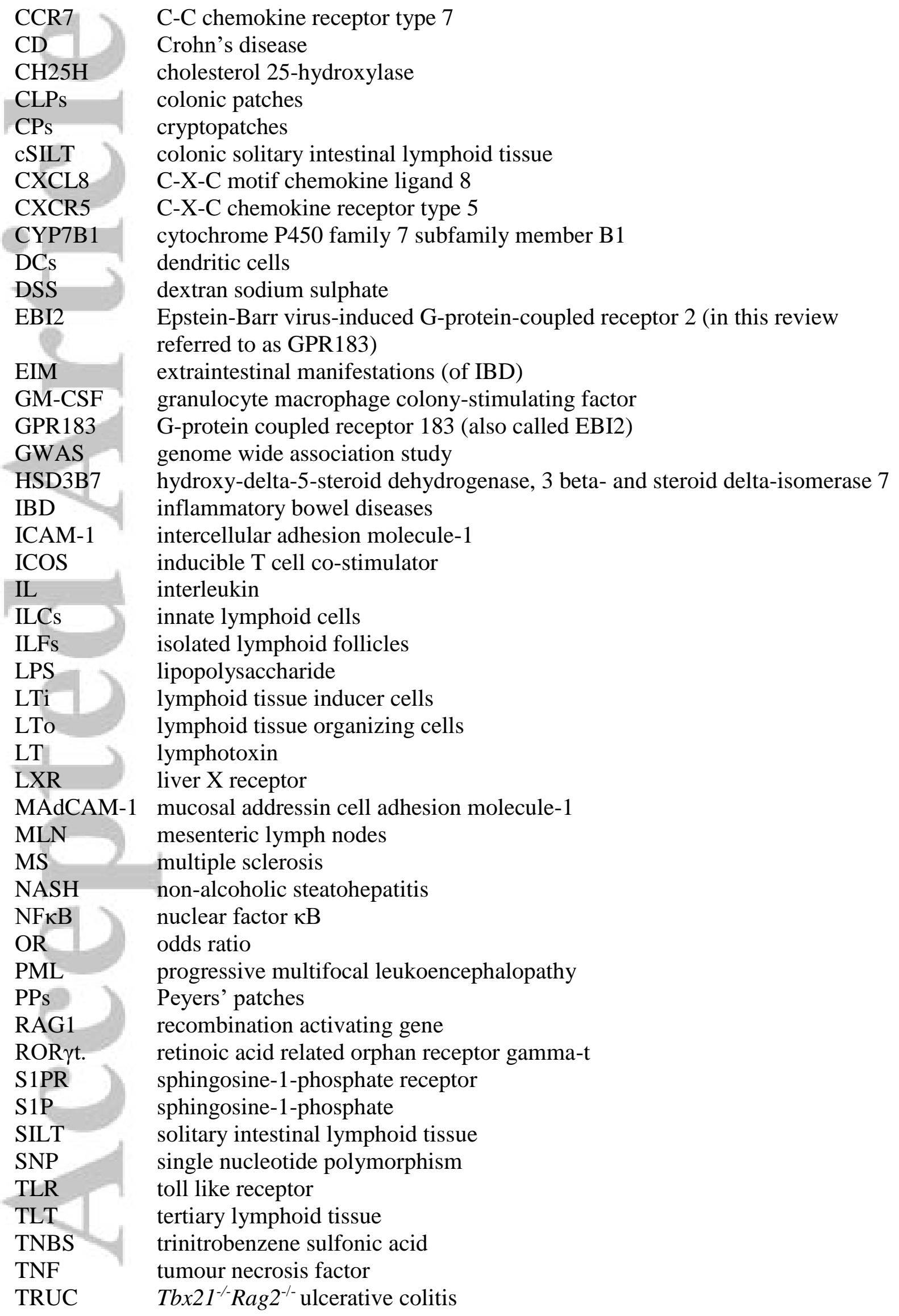


UBAC2 ubiquitin-associated domain-containing gene 2

UC ulcerative colitis

VCAM-1 vascular cell adhesion molecule-1

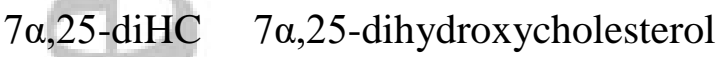

$25-\mathrm{HC}$

25-hydroxycholesterol

\section{Introduction}

In its early days, the field of immune cell migration was dominated by studies on classical adhesion molecules and the chemokine-chemokine receptor system. The study of these systems had opened up exciting therapeutic opportunities in the clinic. However, more recently, additional signals that finely control the movement of distinct immune subsets and their positioning in specific tissues have been identified. Excitingly, these pathways include small molecule metabolites which are well characterised in other systems and link effects of diet, metabolism and the microbiota. Here we focus on one of these systems, the G-protein-coupled receptor 183 ( ${\underline{\mathrm{GPR}} 183^{*}}^{*}$ ), also known as Epstein-Barr virus-induced G-protein-coupled receptor 2 (EBI2) and its cholesterol-derived ligands. We will discuss genetic information, observations in IBD patients and experimental studies implicating GPR183 in IBD pathogenesis and morphogenesis of the intestinal immune system.

\section{Role of GPR183 in the migration and activation of immune cells}

\section{$7 \alpha, 25-\mathrm{diHC}$ is the main ligand of the oxysterol receptor GPR183}

GPR183/EBI2 was discovered in 1993 as an Epstein Barr virus-induced orphan receptor in Burkitt lymphoma cell lines (8). GPR183 ligands remained unknown until 2011, when two landmark publications identified dehydroxylated oxysterols as GPR183 ligands (9, 10). Oxysterols arise from oxidation of cholesterol. $7 \alpha, 25$-dihydroxycholesterol ( $\underline{7 \alpha, 25-\mathrm{diHC}})$ has

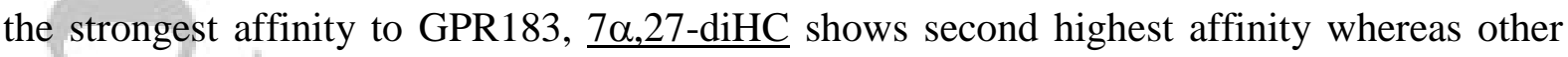
oxysterols (monohydroxylated oxysterols $\underline{25-\mathrm{HC}}$ and $\underline{7 \alpha-\mathrm{HC}}$ ) show substantially lower activity $(9,10)$. Synthesis of the GPR183 ligand $7 \alpha, 25$-diHC requires two hydroxylation steps (Figure 1) at position 25 by the enzyme cholesterol 25 -hydroxylase $(\mathrm{CH} 25 \mathrm{H})$ and at position $7 \alpha$, by cytochrome P450 family 7 subfamily member B1 (YP7B1). Degradation of 7 $\alpha, 25$-diHC is catalysed by the enzyme hydroxy-delta-5-steroid dehydrogenase, 3 beta- and steroid deltaisomerase 7 (HSD3B7) $(9,10)$.

\footnotetext{
* In this article we follow the drug/ molecular target nomenclature of the Concise guide to Pharmacology 7. Alexander SP, Benson HE, Faccenda E, Pawson AJ, Sharman JL, Spedding M, et al. The Concise Guide to PHARMACOLOGY 2013/14: G protein-coupled receptors. British journal of pharmacology. 2013;170(8):1459-581.. Further, nomenclature of proteins and genes follow international conventions: Proteins will be written non-italic (GPR183/ Gpr183), genes in italic (GPR183/Gpr183). Human genes and proteins will be capitalized (GPR183/ GPR183), for mouse proteins genes and proteins only the first letter will be capitalized (Gpr183/ Gpr183). If we refer to the gene/ protein independent from the species, the capitalized form will be used (GPR183/ GPR183).
} 


\section{GPR183 function and its dependence on an oxysterol gradient}

GPR183 is expressed on B cells, T cells, dendritic cells (DCs), macrophages and innate lymphoid cells (ILCs) (3, 5, 9-13). In peripheral blood mononuclear cells, highest levels of GPR 183 are observed on memory lymphocytes, in particular B and CD4 ${ }^{+} \mathrm{T}$ cells but to a lesser extent on $\mathrm{CD}^{+} \mathrm{T}$ cells $(2,14)$. Binding of oxysterols to GPR183 leads to the release of intracellular calcium (9), suppression of cAMP (10) and internalization of GPR183 (10). However, the most important consequence of GPR183 activation is migration of GPR183expressing cells towards higher $7 \alpha, 25$-diHC concentrations $(3,5,9-13,15)$.

In secondary lymphatic organs, enzymes for production of $7 \alpha, 25$-diHC (i.e. Ch $25 h$ and $C y p 7 b 1)$ are expressed by the same and/or neighbouring cells while the enzyme for $7 \alpha, 25$ diHC degradation $(H s d 3 b 7)$ has a divergent expression pattern $(9,10,13,16)$. This suggests that spatial differences in the synthesis and degradation of $7 \alpha, 25$-diHC may result in gradients of oxysterols in lymphoid organs. In agreement with this hypothesis, knockouts of all $7 \alpha, 25-$ diHC-producing and -degrading enzymes (i.e. Ch25h, Cyp $7 b 1$ and $H h s d 3 b 7$ ) recapitulate important aspects of the phenotype of Gprl83 deficiency with respect to $\mathrm{B}$ and $\mathrm{T}$ cell positioning $(9,10,13,16)$. While it is clear that the spatial organization of the enzymatic machinery regulating $7 \alpha, 25$-diHC concentrations in the tissue is indeed important for GPR183 function $(9,10,13,16)$, the postulated $7 \alpha, 25$-diHC gradient has not been visualized yet.

\section{GPR183-dependent positioning of DCs, T and B cells}

For any given antigen only few naïve $\mathrm{B}$ and $\mathrm{T}$ lymphocytes expressing a cognate antigen receptor exist. Due to this large search space, the probability that a given lymphocyte would encounter a specific antigen by chance is very low. Consequently, the generation and coordination of adaptive immune responses rely on cell migration and proper positioning of the interacting cell types. Sophisticated anatomical structures and mechanisms of cell migration have evolved to increase the likelihood of productive cell-cell encounters and enable the efficient generation of adaptive immune responses.

The principal cell types to initiate adaptive immunity are DCs. DCs take up antigens, process them and transport them to specific sites where they encounter and activate lymphocytes. Thereby, DC migration, proper positioning of DCs and lymphocytes within immune compartments and the anatomical organization of the immune system increase the probability of antigen-presenting DCs to encounter cognate lymphocytes and hence the efficacy of adaptive immunity. Two main subsets of conventional DCs (cDCs) have been described. Broadly, the cDC1 subset plays a key role in CD8 T cell responses whereas the cDC2 subset preferentially interacts with CD4 $\mathrm{T}$ cells $(17,18)$. While upon toll-like receptor (TLR) stimulation, GPR183 expression is upregulated on $\mathrm{cDC} 2 \mathrm{~s}$, $\mathrm{cDC} 1 \mathrm{~s}$ don't seem to express GPR183 (19). GPR183 contributes at various levels to the coordination of cell-cell encounters by modulating the migration and positioning of DCs, T cells and B cells.

GPR183 supports localization of cDC2s at the bridging channel in the spleen and the periphery of lymph node $\mathrm{T}$ cell zones, both of which are locations where antigens accumulate and antigen uptake and presentation to $\mathrm{T}$ cells may occur $(11,12)$. Additionally, GPR183 promotes 
migration of lymphocytes to the interface between lymph node follicles and the $\mathrm{T}$ cell zone, aiding contact with DCs (13). These contacts facilitate differentiation of activated $\mathrm{T}$ cells to

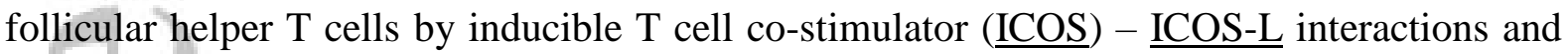
DC-mediated quenching of $\underline{\text { CD25 }}$ signalling (13).

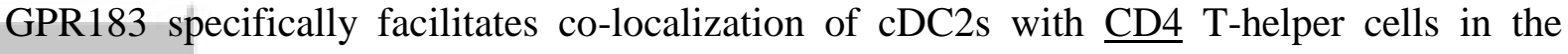
peripheral $\mathrm{T}$ cell zone as well as antigen-dependent CD4 $\mathrm{T}$ cell activation and expansion. In mice, Gpr183 was required for CD4 $\mathrm{T}$ cell-dependent protection against helminths and successful plasmodium vaccination (20).

For the activation of B cells in secondary lymphoid organs, GPR183 synergizes with the C-C chemokine receptor type 7 ( $\underline{\mathrm{CCR} 7})$ to position $\mathrm{B}$ cells at the $\mathrm{B}-\mathrm{T}$ zone interphase (Figure 3 ). After having received T cell help, B cells downregulate CCR7 and move to interfollicular and outer follicle regions $(9,10,16,21-23)$. Importantly, vaccination-induced plasma IgG1 responses were reduced in Gprl83 knockout mice as compared to wild type animals (9). Thus, GPR183 is important for rapid and efficient B cell activation.

\section{GPR183-dependent migration of ILCs in the intestine}

Besides supporting the migration of lymphocytes and DCs, GPR183 coordinates the migration of innate lymphoid cells (ILCs). ILCs are innate counterparts of T lymphocytes. Like conventional T cells, ILCs are potent producers of cytokines and are derived from the same common lymphoid progenitor. However, unlike T cells, ILCs lack specific T cell receptors (2428). ILC1 mirror the functionality of Th1 cells and respond to intracellular pathogens, ILC2s secrete cytokines, which play an important role in anti-parasite and allergic responses and ILC3, like their Th17 counterparts, can participate in defence against extracellular microbes. Since ILCs do not require clonal expansion for their function, they are able to respond without delay to appropriate signals.

In the intestinal mucosa, ILC3s are the dominant type of ILCs and contribute to immunity and barrier integrity (29). ILC3s are characterized by expression of transcription factor retinoic acid related orphan receptor gamma-t ( $\underline{\mathrm{ROR} \gamma \mathrm{t}})$. ILC3s contain commensal bacteria (30) and support defence against enteropathogens $(27,29)$. Interleukin (IL)-22 is a key cytokine produced by ILC3s that stimulates secretion of antibacterial peptides (31) and also contributes to antiviral defence (32).

Gpr183 is expressed at higher levels on ILC3s in the intestinal lamina propria $(3,5)$ compared to blood (2) and ILC3s have been shown to migrate towards a $7 \alpha, 25$-diHC gradient (5). GPR183 can promote accumulation of ILC3s in the intestine. In experiments with mixed bone marrow chimeras, Gpr183-expressing ILC3 cells clustered in solitary intestinal lymphoid tissue (SILT) of colonic and small intestinal tissue (3), while $G$ pr $183^{-/-}$cells accumulated in the mesenteric lymph nodes (5).

Gpr183 expression on ILC3s mediates protection against enteric bacterial infections and Gpr183 deficiency resulted in more severe inflammation in the model of Citrobacter rodentium induced colitis. In line with a role of ILCs in this phenotype, Rag ${ }^{-/} \mathrm{Gpr}_{183^{--}}$mice had lower 
numbers of ILC 3 and lower numbers of IL-22 producing ILC3 in the small intestine and in the colon (5).

\section{Fine-tuning of oxysterol gradients}

As described above, the generation of the high-affinity GPR183 ligand 7 $\alpha, 25$-diHC requires the sequential activity of $C H 25 H$ and $C Y P 7 B 1$. However, $C h 25 h$ knockout mice only partially replicate the phenotype of $\operatorname{Gpr} 183$ deficiency (2, 3, 19). Similarly, Ch25h and Cyp7b1 knockouts differ with respect to their effects on DC positioning. These observations suggest a more complex machinery producing and degrading GPR183 ligands. Indeed, the enzyme Cyp27al with 27-hydroxylating activity is able to generate the alternative GPR183 ligand $7 \alpha, 27$-diHC (19). 7 $\alpha, 27$-diHC basically recapitulates $7 \alpha, 25$-diHC signalling via GPR 183 , even though 10-fold higher concentrations are required $(9,10,19)$ and $7 \alpha, 27$-diHC might result in

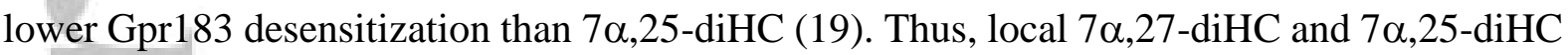
availability in secondary lymphoid organs might fine-tune GPR183 signalling. Close spatial expression (including co-expression by the same cell) of the enzyme pairs Ch25h and Cyp $7 b 1$ or Cyp27al and Cyp7b1 would favour generation of $7 \alpha, 25$-diHC or $7 \alpha, 27-\mathrm{diHC}$, respectively.

Oxysterol levels can also be regulated by degradation pathways. In the spleen, activation of the cDC1 subset (not expressing Gpr183, see above) further influenced positioning of the Gpr183expressing cDC2 subset. cDC1s express the oxysterol-degrading enzyme Hsd3b7 and the activity of Hsd3b7 may prevent movement of GPR183 expressing cells into the vicinity of cDC1s by the degradation of oxysterol gradients (19).

So far, oxysterol gradients in tissues cannot be directly visualized. GPR183 ligands are generated via $7 \alpha$-hydroxylation (CYP7B1) and 25-hydroxylation (CH25H, $\underline{\mathrm{CYP} 3}$ and CYP46A1) (33) or 27-hydroxylation (CYP27A1) activity (19). A more detailed understanding of the GPR183-oxysterol system will require a better definition of the spatio-temporal dynamics of GPR183 ligand generation and degradation.

Direct effects of GPR183 activation on immune cell function

GPR183 is a well-characterized G-protein coupled receptor and many biological effects of GPR183 described so far involve cellular migration and positioning. However, there is mounting evidence suggesting additional intracellular effects of GPR183. Interestingly, GPR183 has been discovered in an siRNA screen as a host factor for Mycobacterium tuberculosis infection in human macrophages (34). In murine macrophages, overexpression of Gpr183 promoted intracellular Mycobacterium tuberculosis replication while knockdown, mutation or chemical inhibition of Gprl83 reduced Mycobacterium tuberculosis infection (35). Gpr183 expression and activity was also critical in a tissue culture model of non-alcoholic steatohepatitis (36). Further investigation into the direct effects of GPR183 on effector cells of the immune system would open a new layer of complexity and opportunities for more discoveries. 


\section{GPR183 in lymphoid organogenesis}

\section{Development of the intestinal immune system}

The gut associated lymphoid tissue (GALT), comprising distinct immune compartments such as large encapsulated Peyer's patches (PPs) and isolated intestinal follicular structures, initiates and regulates intestinal immune responses. Recent reports reveal how GPR183 contributes to the organization of intestinal lymphoid tissue $(2,3,5)$. Before reviewing the role of GPR183 in lymphoid organogenesis, we will briefly summarize key aspects of intestinal lymph organogenesis using the example of Peyer's patches and introduce key features of different GALT structures (see textbox).

Like lymph nodes, PPs are formed during gestation (37). A centre stage in PP organogenesis is taken by hematopoietic lymphoid tissue inducer cells (LTi), which are a subtype of ILC3s. LTi interact with stromal cells known as lymphoid tissue organizing cells (LTo). LTi express lymphotoxin, which binds to lymphotoxin receptor on LTo. Lymphotoxin signalling triggers expression of the chemokine $\underline{\text { CXCL13 }}$ to recruit LTi expressing the chemokine receptor CXCR5 and induces survival and retention of LTi. Clusters of LTi subsequently recruit additional immune cells for formation of mature lymphoid structures $(38,39)$.

PPs resemble lymph nodes with respect to their typical organization of distinct $\mathrm{B}$ and $\mathrm{T}$ cell zones (even though at different proportion in PP as compared to lymph nodes). The colonic equivalent to small-intestinal PPs are colonic patches (CLPs). Like PPs, CLPs are formed during gestation. They are located in the muscularis mucosae and 'touch' the intestinal lumen (Figures 3,4). However, intestinal immune responses are also supported by additional mucosal lymphoid tissues (see below). Some intestinal immune structures, such as PPs, develop independently from inflammation as secondary lymphoid tissues but tertiary lymphoid tissue is also induced in response to chronic inflammation.

Solitary intestinal lymphoid tissue (SILT) is a type of GALT with features between bona fide secondary and tertiary lymphoid tissues (Figures 3, 4). SILTs are strictly submucosal structures, close to the intestinal epithelium of the small and large intestine (1). By definition, SILTs never invade or penetrate the muscularis propria. In contrast to lymph nodes, PPs and CLPs, SILTs only appear after birth (37) and development of SILTs requires the presence of LTi (40), lymphotoxin (41) and TLR signalling (1, 42, 43), compare textbox.

Different maturation stages of SILTs can be distinguished. The smallest structures are referred to as cryptopatches (CPs) and comprise mostly LTi and LTo cells, surrounded by DCs. Larger SILTs are known as isolated lymphoid follicles (ILFs). ILFs can reach the size of a PP or CLP and also contain organized B cell follicles. At least in humans, T cell areas and $\underline{\text { MadCAM-1 }}^{+}$ vessels for immune cell recruitment were demonstrated (44). Recruited B cells have been shown to undergo $\mathrm{T}$ cell-independent class-switch recombination within ILFs. Thus ILFs may be a critical source of T cell-independent IgA (45).

Impact of GPR183 on the development of colonic SILTs (cSILTS)

Several recent studies demonstrated that GPR183 is required for the development of lymphoid tissue in the colon. Gpr183 knockout mice show a lower number of B-cell positive lymphoid 
structures $(2,3,5)$. Microscopic examination revealed that colonic SILTs (cSILTs) were mainly affected, while the number of CLPs was constant (2) or only slightly reduced (3). Detailed experiments with conditional Gpr183 knockouts demonstrated that GPR183 expression by LTi-like ILC3s is required for generation of colonic SILTs while it is dispensable for the formation of colonic patches (3).

Gprl83 knockout impacted less on the development of SILTs in the small intestine: in one study, the overall number of ILC3s in the small intestinal lamina propria was lower in Gpr $183^{-1-}$ and $C h 25 h^{-/-}$mice and there were also fewer cryptopatches in the small intestine (5), while in another study, the number of small intestinal SILTs was only marginally reduced (3). Most likely, the GPR183-7 $\alpha, 25-$ diHC axis is also active in the small intestine, mediating recruitment of immune cells. However, B cells seem to be able to compensate for loss of LTilike ILC3 function in the small intestine, but not in the colon (3).

Immune cell migration into CPs and ILFs is dependent on $\mathrm{Ch} 25 \mathrm{~h}$ activity, which is required for synthesis of the GPR 183 ligand 7 $\alpha, 25$-diHC. More detailed evaluations revealed expression of the 7a,25-diHC producing enzymes Cyp7b1 and Ch25h in CD34-podoplanin ${ }^{+}$fibroblasts

within ILFs, while CD34+ $4^{+}$odoplanin ${ }^{+}$fibroblasts outside ILFs produced the $7 \alpha, 25$-diHC degrading enzyme Hsd3b7 (3). This differential enzyme expression pattern suggests existence of a 7 $\alpha, 25$-diHC gradient around SILTs which would mediate the recruitment of Gpr183 expressing ILC3s, B cells and DCs into SILTs.

Despite these profound alterations of the GALT of Gprl83 knockout mice, their intestinal immune system remained intact and no further impairment of functionality could be detected in the absence of environmental challenges: The number of mesenteric lymph nodes and the total number of $\mathrm{B}$ cells in the colon was normal with normal faecal $\operatorname{IgA}$ levels $(2,3)$. Furthermore, no differences in microbiota composition were found in Gpr183 deficient mice and the fraction of IgA coated bacteria remained normal (2). Interestingly, in colonic ILC 3s, Il-22 production was reduced upon Gpr183 knockout (3).

\section{GPR183 in intestinal inflammation}

The GPR183 locus is a risk locus for inflammatory bowel diseases

Inflammatory bowel diseases are chronic inflammatory conditions and comprise the major subgroups Crohn's disease (CD) and ulcerative colitis (UC). While in UC disease activity is restricted to the colon with strongest inflammatory activity in the rectum, CD can affect the whole intestinal tract. The pathogenesis of IBD is unknown but genetic and environmental risk factors have been identified $(46,47)$.

Genome wide association studies (GWAS) have linked the GPR183-oxysterol system to IBD. GWAS identified $>240$ genetic regions and most identified genes increased the risk for both, UC and CD (48-51). One IBD risk gene maps to the genetic region encoding GPR183. The single nucleotide polymorphism (SNP) rs9557195 on chromosome 13 within an intron of GPR183 (Figure 5) is associated with CD (odds ratio (OR) of 1.12; 95\% CI: 1.08-1.16) and UC (OR 1.1; 95\% CI 1.06-1.15) (48). Association of SNP rs9557195 with both UC and CD, suggests a potentially more general role of the GPR183 locus for inflammatory mechanisms 
and/or organization of the gastrointestinal immune system. Very recent data from our group indicate increased GPR183 expression on the surface of immune cells in individuals with the CC-allele of rs9557195 [F. Ruiz, C. Pot, B. Misselwitz manuscript submitted], providing the first experimental confirmation of these genetic data in human samples.

The UBAC2 gene is a second gene at the GPR183 locus and associated with Behçet's disease

The architecture of the human GPRl83 gene locus is complex. The ubiquitin-associated domain-containing gene 2 (UBAC2) is located on the complementary DNA strand and contains several intron and exon regions overlapping with GPR183 (Figure 5). GPR18, another Gprotein coupled receptor, also overlaps with $U B A C 2$. Several studies associated SNPs within the $U B A C 2$ gene with the risk for Behçet's disease (52-54). Behçet's disease is a rare condition but more frequently occurring along the ancient silk road from Eastern Asia to Mediterranean with most cases in Turkey (55).

Behçet's disease is a small vessel vasculitis, diagnosed upon occurrence of recurrent bipolar (oral and genital) aphthae and additional systemic manifestations with involvement of eyes, skin (erythema nodosum and pyoderma gangraenosum), the nervous system and joints. Gastrointestinal involvement occurs in $10-15 \%$ of patients with abdominal pain, diarrhoea and intestinal ulcerations frequently in the ileocecal region $(56,57)$.

Manifestations of Behçet's disease may thus overlap with intestinal and extraintestinal manifestations (EIM) of CD, making a correct disease diagnosis challenging (56). Further, IBD and Behçet's disease respond to similar medical treatments (57) and have genetic overlap (58). It is therefore possible that Behçet's disease mutations contribute to the risk of EIM in IBD but the clinical relevance of the overlap of IBD with Behçet's disease remains unknown.

UBAC2 expression was increased in peripheral blood mononuclear cells in patients carrying risk alleles of two Behçet's disease-associated SNPs (rs7999348 and rs3825427, Figure 5) (52, 53). UBAC2 is part of an endoplasmic reticulum (ER) membrane protein complex, which can inhibit wnt/ $\beta$-catenin signalling, and defects of other proteins in this complex result in severe lymphocyte dysfunction (59). In another study, UBAC2 restricted trafficking of ubiquitin-likedomain-containing protein 8 (also called FAF2) from the ER to lipid droplets (60). Besides UBAC2, other ubiquitination-related genes (UBASH3B, SUMO4) have also been associated with Behçet's disease, suggesting a crucial role of ubiquitination in the pathogenesis of this condition $(52,53,61)$. However, it remains unclear how UBAC2 can contribute to organ inflammation.

The IBD-associated SNP rs9557195 is located within introns of both genes, GPR183 and $U B A C 2$, and it remains unclear how much each of those genes contributes to IBD risk. rs9557195 might act via GPR183 since it is associated with the risk for both CD and UC, while Behçet's disease mainly overlaps with CD. Further, our unpublished observations show increased GPR183 expression in individuals with the rs9557195-CC allele (see above).

However, in CD patients resistant to anti-tumour necrosis factor (TNF) treatment, an expression quantitative trail loci (eQTL) study identified elevated UBAC2 levels in individuals 
with the rs9557195-TT genotype in peripheral blood and the intestine (62). Further, rs3742130, another SNP within UBAC2/GPR18 was associated with anti-TNF non-responsiveness (63), raising the possibility of involvement of UBAC2 in IBD as well. However, none of the studies of either GPR183 or UBAC2, rigorously excluded the effects of the other gene, hence a role of both genes in IBD is possible.

\section{Murine models of IBD suggest proinflammatory effects of GPR183}

Experimental observations indicate an important role of GPR183 in inflammation and pathogenesis of colitis. In the anti-CD40 colitis model, colon inflammation is induced by injection of the anti-CD40 antibody into $\mathrm{Ragl}^{-/-}$mice. Reduced overall inflammation and fewer inflammatory foci containing Gpr183 expressing ILC3s and myeloid cells were observed in

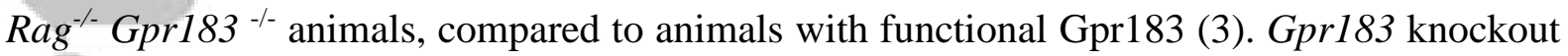
also reduced granulocyte macrophage colony-stimulating factor (GM-CSF) production (3), which had been suggested as a key pro-inflammatory activity of ILC3s in innate colitis.

Similarly, GPR183 confers pro-inflammatory effects in the IL-10 model of chronic colitis: Gpr $183^{-/} \mathrm{Il}-10^{-/-}$animals had less severe inflammation compared to $\mathrm{Il}-10^{-/}$controls (2). Notably, the IL-10 colitis model shows at least some relevance for human IBD, since $I L-10$ mutations have been linked to the human disease (64). Interestingly, in IL-10 colitis, the Gpr183 phenotype was restricted to male animals (2). The reason for this sex-difference is unclear but related observations have also been reported in other colitis models (65). Further, in humans, polymorphisms in the IL-10 gene can also act in a gender specific manner (66) and CYP7B1, one of the enzymes necessary for $7 \alpha, 25$-diHC production, is a male dominant gene (67). In any case, mechanistic effects how Gpr183 increased colon inflammation in Il-10 colitis remain unclear.

In contrast, in acute and chronic chemical (dextrane sodium sulphate: DSS) colitis, knockout of Gpr183 did not affect intestinal inflammation (2). This suggests that GPR183 effects on intestinal inflammation depend on the particular system and mode of pathogenesis.

Intestinal inflammation affects balancing of the GPR183-oxysterol system

GPR183 mRNA levels as well as mRNA of enzymes producing 7 2,25 -diHC $(\mathrm{CH} 25 \mathrm{H}$, $C Y P 7 B 1$ ) are upregulated in biopsies of UC patients with active disease compared to patients in remission or healthy controls (2). Expression levels correlated with disease activity and established inflammatory markers including TNF or C-X-C motif chemokine ligand 8 (CXCL8) expression (2, 3). GPR183 expression was also induced by lipopolysaccharide (LPS) on human macrophages $(10,68,69)$, with possible repression in the murine system $(69,70)$, possibly related to ligand-induced GPR183 downregulation.

In murine colitis, activation of the GPR183-7 $\alpha, 25$-diHC axis was also observed and confirmed by oxysterol measurements. Most experiments were done in the acute and chronic DSS colitis model, which relies on chemical destruction of the intestinal barrier and innate immune activation. Measurements in acute DSS colitis confirmed increased expression of Gprl83, Cyp7bl and Ch25h in the gut $(2,71)$ and higher levels of the oxysterols $4 \beta-\mathrm{HC}, 25-\mathrm{HC}$ and $7 \alpha, 25$-diHC in the gut mucosa $(2,72,73)$. Similar changes, correlating with colitis severity, 
were observed in chronic DSS colitis (72). In one study, 7 $\alpha, 25$-diHC was elevated in colon and stool and usage of 7 $\alpha, 25$-diHC as a biomarker was suggested for IBD (73). Trinitrobenzene sulfonic acid (TNBS) induced colitis resulted in increased levels of $4 \beta-\mathrm{HC}, 25-\mathrm{HC}$ but not $7 \alpha, 25$-diHC (72). Increased $C h 25 h$ expression and production of an activity, stimulating Gpr183 dependent cell migration was also observed in innate anti-CD40 colitis (3).

While an increase in $25-\mathrm{HC}$ and $7 \alpha, 25$-diHC was repeatedly observed, expression levels of Cyp27al (responsible for production of $27-\mathrm{HC}$ and the alternative GPR183 ligand 7 $\alpha, 27$ diHC) were not affected in IL-10, DSS or TNBS colitis $(2,72)$, while Hsd3b7 levels (responsible for degradation of most oxysterols) were normal or even decreased $(2,72)$.

Upregulation of oxysterol synthesis and increased oxysterol concentrations were also observed in human and murine models of non-alcoholic steatohepatitis (NASH) but knockouts of Gpr183, Cyp7b1 or Ch25h did not affect severity of NASH (74).

In summary, there is strong and consistent evidence for increased expression of the enzymes synthesizing the GPR183 ligand 7 $\alpha, 25$-diHC in human samples and four different mouse models of colitis and enzyme levels correlate with severity of inflammation. In biochemical analyses, higher intestinal 7 2,25 -diHC levels were observed in murine tissue upon inflammation in most models $(2,3,72,73)$. However, levels of other oxysterols varied to a higher degree. Most likely, the degree of systemic and local inflammation differed according to the mouse models used. Further, mass spectrometry determinations of di-hydroxylated oxysterols can be challenging, likely explaining most discrepancies.

Non-GPR183 mediated effects of oxysterols in intestinal inflammation

While pro-inflammatory effects of GPR183 in inflammation are increasingly recognized, it has long been established that oxysterols are immune-modulatory molecules with broad activities (75) (Table 1).

The induction of $\mathrm{CH} 25 \mathrm{H}$ is a general feature in inflammation. Several TLR agonists increased $\mathrm{CH} 25 \mathrm{H}$ mRNA levels and increased $25-\mathrm{HC}$ production in human and murine macrophages (10, $68,76-80)$. In line with these results, in human healthy volunteers, serum 25 -HC concentration increased upon LPS injection (77).

25-HC also has broad immune-modulatory effects. It is a powerful inhibitor of human viruses $(78,79)$ and was very recently identified as an efficient antibacterial molecule in Listeria monocytogenes and Shigella flexneri infection (81). Antibacterial effects are mediated by redistribution of membrane cholesterol and reduction of accessible membrane cholesterol (81). 25-HC also inhibits inflammasome assembly, caspase activation and $\underline{\text { LL-1 }}$ and $\underline{\text { LL-18 }}$ production in macrophages (82) while IL-1 can in turn induce Th-17 differentiation (83).

Therefore, not all effects of oxysterols in intestinal inflammation are mediated by GPR183 (Table 1 ) and the oxysterol receptors liver $X$ receptor (LXR)- $\alpha$ and LXR- $\beta$ have a role in colitis. LXR- $\alpha$ and LXR- $\beta$ are activated by oxysterols including $25-\mathrm{HC}$ and $27-\mathrm{HC}$ (84). More severe DSS colitis was observed upon knockdown of $L x r-\beta$ and/ or $L x r-\alpha$ while the LXR agonist GW3965 improved clinical course of DSS colitis (85). Thereby, Lxr- $\beta$ and Lxr- 
$\alpha$ reduced activation of $\mathrm{CD}_{11 \mathrm{~b}^{+}}$immune cells, while $\operatorname{Lxr}-\beta$ in addition downregulated secretion of inflammatory mediators in colonic epithelial cells (85). Recent experiments have also associated $\mathrm{Ch} 25 \mathrm{~h}$ with intestinal fibrosis in two animal models (71).

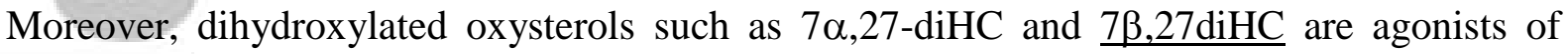
ROR $\gamma$ t and regulate Th17 cell differentiation (86). Since Th17 cells have been shown to be of relevance in IBD pathogenesis (87) oxysterol mediated ROR $\gamma$ t stimulation is likely relevant in IBD. Distinguishing GPR183-mediated effects of oxysterols from effects on LXR, ROR $\gamma \mathrm{t}$ and pleiotropic oxysterol effects (see below) remains a challenge.

\section{GPR183-dependent accumulation of lymphoid tissue in chronic colitis}

Whereas colonic patches are clearly distinct in their anatomical localization and structure, cSILT and TLT in the colon cannot easily be distinguished by histology and foremost differ in their developmental requirements. Thus, lymphoid tissue observed in the inflamed colon might represent true TLT and/or more mature and/or hypertrophic cSILT.

Build-up of colonic lymphoid tissue seems to require a prolonged inflammatory stimulus: no changes of cSILT/TLT numbers were seen in acute DSS colitis, while in chronic DSS colitis a pronounced increase of cSILTs/TLTs could be observed (88). Accumulated lymphoid tissue comprises B cells with germinal centres, DCs and CD4 T cells but no T cell areas. High endothelial venules are frequently observed around inflammation-induced TLTs, which would facilitate further recruitment of immune cells (89).

Accumulation of TLTs in chronic inflammation is dependent on GPR183: in chronic chemical (DSS) colitis, in $\mathrm{Gpr} 183^{-{ }^{-}}$animals, low cSILT/TLT numbers were seen at baseline without any inflammation dependent increase, despite similar levels of inflammation in $\mathrm{Gpr}_{183^{-/}}$and wildtype animals (2). Interestingly, the increase in cSILT/TLT was only partially dependent on $C h 25 h$, suggesting activity of either Cyp27a1 (for production of $7 \alpha, 27$-diHC) or activity of other enzymes with 25-hydroxylation activity (see above).

Inflammation in chronic Il-10 colitis also increased the number of cSILTs/TLTs with a strong correlation of the number of lymphoid structures and the level of inflammation (2). Upon Gpr183 knockout, an overall lower number of SILTs was observed even in animals with similar levels of inflammation (2). In innate anti-CD40 colitis, Gpr183 was also required for an inflammatory migratory response and induction of lymphoid tissue during inflammation (3). Therefore, there seems to be a universal requirement for Gpr183 for the induction of inflammatory lymphoid tissue, independent from the way colon inflammation was induced.

For induction of SILTs in inflammation, B cells might be able to take on the function of LTis. In chronic DSS colitis, accumulation of lymphoid tissue required lymphotoxin but not ROR $\gamma \mathrm{t}$ and the authors demonstrated a critical function of B cells for induction of lymphoid tissue upon ROR $\gamma$ t knockout (88). Since GPR183 is expressed on ILCs and B cells, GPR183 might support both, the classical LTi (ILC3)-dependent induction of cSILTs as well as the alternative B cell dependent pathway, described above. However, this still needs to be confirmed directly.

A recent study indicated that ILC3s were predominantly localized in CPs but ILC3 motility increased after induction of anti-CD40 colitis resulting in preferential ILC 3 s egress from CPs 
(90). It is unclear whether this change of motility depends on GPR183 and whether it is related to inflammation and/ or accumulation of lymphoid tissue.

The detailed function of the accumulated colonic lymphoid tissue in chronic colitis is unclear. It is unknown whether they have more pro-inflammatory or anti-inflammatory properties in the context of infection or IBD and discrepant results have been described in different models (91). While in some murine studies, colitis was dependent on accumulated cSILT/TLT (3, 88, 92, 93), in other studies no correlation between cSILTs/TLTs and chronic inflammation was observed $(2,94)$. Accumulation of lymphoid follicles and lymphangitis are also a hallmark of human small intestinal Crohn's disease but pathogenesis and implications for management of these findings are insufficiently understood $(91,95,96)$.

In summary, recruitment of immune cells into the colon upon chronic inflammation remains a complex process (Table 1) and CXCL13, $\underline{\mathrm{IL}-22}, \underline{\mathrm{IL}-23}, \underline{\text { lymphotoxin, the microbiota }(6,88,92)}$ and possibly also the CXCR5-CXCL13 axis (97) have been implicated. Recent data also indicate a role of GPR183 in this process (2). Further studies of GPR183 in intestinal inflammation might also reveal relevance and functional impact of lymphoid tissue accumulation in colitis.

\section{The GPR183-oxysterol axis as a potential drug target for IBD}

\section{Targeting immune cell migration}

Inhibition of immune cell migration is a well-established therapy principle in IBD and other inflammatory conditions. Current approaches include integrin inhibition, sphingosin-1phosphate receptor (S1PR) modulation and chemokine receptor blockage. GPR183 modulation might constitute a new therapeutic approach, non-redundant with established therapies and with potentially unique effects.

Integrin inhibitors have been the first approved drugs to block cellular migration. Homing of immune cells into the gut is mediated by integrin- $\alpha 4 \beta 7$. Natalizumab (blocking the integrin$\alpha 4$ subunit) and vedolizumab (blocking integrin- $\alpha 4 \beta 7$ ) are of therapeutic value in IBD (98101). Natalizumab (102) (but not the gut specific vedolizumab (103)) is associated with the risk of the opportunistic infection progressive multifocal leukoencephalopathy (PML). Therefore, natalizumab is rarely if ever used in IBD. However, in patients with multiple sclerosis (MS) under natalizumab treatment, GPR183 expression and activity is increased on the surface of CD4 memory $\mathrm{T}$ cells compared to before treatment (14), suggesting high GPR183 expression in immune cells destined to target inflamed tissues such as the brain in MS and/ or the intestine (104).

S1PR mediate exit of lymphocytes from secondary lymphoid organs. Lymphocytes follow a sphingosine-1-phosphate (S1P) gradient with higher S1P concentrations in blood. S1PR blockade results in functional inactivation of lymphocytes by trapping them within lymphoid organs (105). Ozanimod (blocking S1PR1 and S1PR5) showed some activity in UC patients. In line with entrapment of lymphocytes as the mode of action for ozanimod, peripheral lymphocyte counts decreased by almost $50 \%(106,107)$.

This article is protected by copyright. All rights reserved. 
Chemokine receptors $\underline{\mathrm{CCR} 6}, \underline{\mathrm{CCR} 9}$ and $\underline{\mathrm{CXCR} 3}$ and its ligands mediate recruitment of immune cells into the gut in health and/ or inflammation; however, clinical tests of blocking these chemokine receptors in IBD remained disappointing (108-112), most likely due to redundant migratory signals for immune cell recruitment into the inflamed gut.

Effects of GPR183 inhibition would likely differ from inhibition of integrins, S1PR and chemokine receptors. In animal experiments, GPR183 knockout did not reduce the overall number of intestinal lymphocytes, but affected immune cell distribution in the intestine with reduction of SILTs $(2,3)$ and entrapment of lymphocytes in mesenteric lymph nodes (5). In inflammation, GPR183 mediated accumulation of tertiary lymphoid follicles in the mucosa with pro-inflammatory effects in some but not all animal models (2, 3). Since our understanding of the function of SILTs in health and inflammation is limited, effects of GPR183 inhibition in human IBD is not foreseeable, but the opportunity of a new drug target in intestinal inflammation is highly welcome.

Blocking of the GPR183-oxysterol axis

A chemical inhibitor which prevents binding of $7 \alpha, 25$-diHC to GPR183 and hence $7 \alpha, 25$-diHC dependent migration of immune cells can be used as an GPR183 blocker $(113,114)$. In mice, this inhibitor replicated DC positioning phenotypes of the Gprl83 knockout (19), but has not been tested in murine colitis.

Targeting oxysterol synthesis, such as blocking Cyp7b1 by clotrimazole (10), could be used as additional therapeutic strategy. However, to the best of our knowledge, knockouts of $C y p 7 b 1$, Ch25h or Cyp27al have not been tested in Gpr183 dependent colitis models so the therapeutic potential for IBD remains unexplored. Conversely, in mice, application of 25-HC drastically changed oxysterol levels (including $7 \alpha, 25$-diHC) but did not alter severity of DSS colitis (72).

\section{Conclusion and outlook}

The immune system is organized in a multi-layered, fractal-like manner. GPR183 is a key factor involved in the spatial organization of the immune system and in particular the development of lymphoid tissues in the intestine. Human genetics and animal experiments have suggested a role of GPR183 in colitis. However, for now, we are still far from understanding the function of GPR183 in intestinal inflammation. Of note, it remains unclear whether the effects of the IBD polymorphism rs9557195 are mediated via GPR183 or UBAC2. Furthermore, the mechanisms by which GPR183 promotes intestinal inflammation in some, but not all animal models has not been clarified. Moreover, the impact of GPR183 mediated accumulation of lymphoid tissue in colitis, and its impact on inflammation and healing are unclear. Finally, broad immune-modulatory effects of oxysterols and possible direct effects of GPR183 on immune cells have been described and need further study to be distinguished from the effects of GPR183 on cell motility and migration. Notably, downstream effects of GPR183 inhibition, disrupting intestinal immune cell distribution may be unique and different from all other cellular migration inhibitors and warrant further efforts to assess the therapeutic potential for GPR183 inhibition in IBD.

This article is protected by copyright. All rights reserved. 


\section{Nomenclature of targets and ligands}

Key protein targets and ligands in this article are hyperlinked to the corresponding entries in http://www.guidetopharmacology.org, the common portal for data from the IUHAR/BPS Guide to pharmacology (115), and are permanently archived in the Concise Guide to PHARMACOLOGY 2019/20 (7).

\section{References}

1. Baptista AP, Olivier BJ, Goverse G, Greuter M, Knippenberg M, Kusser K, et al. Colonic patch and colonic SILT development are independent and differentially regulated events. Mucosal Immunol. 2013;6(3):511-21.

2. Wyss A, Raselli T, Perkins N, Ruiz F, Schmelczer G, Klinke G, et al. The EBI2-oxysterol axis promotes the development of intestinal lymphoid structures and colitis. Mucosal Immunol. 2019;12(3):733-45.

3. Emgard J, Kammoun H, Garcia-Cassani B, Chesne J, Parigi SM, Jacob JM, et al. Oxysterol Sensing through the Receptor GPR183 Promotes the Lymphoid-Tissue-Inducing Function of Innate Lymphoid Cells and Colonic Inflammation. Immunity. 2018;48(1):120-32 e8.

4. Velaga S, Herbrand H, Friedrichsen M, Jiong T, Dorsch M, Hoffmann MW, et al. Chemokine receptor CXCR5 supports solitary intestinal lymphoid tissue formation, B cell homing, and induction of intestinal IgA responses. J Immunol. 2009;182(5):2610-9.

5. Chu C, Moriyama S, Li Z, Zhou L, Flamar AL, Klose CSN, et al. Anti-microbial Functions of Group 3 Innate Lymphoid Cells in Gut-Associated Lymphoid Tissues Are Regulated by GProtein-Coupled Receptor 183. Cell Rep. 2018;23(13):3750-8.

6. Olivier BJ, Cailotto C, van der Vliet J, Knippenberg M, Greuter MJ, Hilbers FW, et al. Vagal innervation is required for the formation of tertiary lymphoid tissue in colitis. Eur J Immunol. 2016;46(10):2467-80.

7. Alexander SP, Benson HE, Faccenda E, Pawson AJ, Sharman JL, Spedding M, et al. The Concise Guide to PHARMACOLOGY 2013/14: G protein-coupled receptors. British journal of pharmacology. 2013;170(8):1459-581.

8. Birkenbach M, Josefsen K, Yalamanchili R, Lenoir G, Kieff E. Epstein-Barr virusinduced genes: first lymphocyte-specific $\mathrm{G}$ protein-coupled peptide receptors. J Virol. 1993;67(4):2209-20.

9. Hannedouche S, Zhang J, Yi T, Shen W, Nguyen D, Pereira JP, et al. Oxysterols direct immune cell migration via EBI2. Nature. 2011;475(7357):524-7.

10. Liu C, Yang XV, Wu J, Kuei C, Mani NS, Zhang L, et al. Oxysterols direct B-cell migration through EBI2. Nature. 2011;475(7357):519-23.

11. Gatto D, Wood K, Caminschi I, Murphy-Durland D, Schofield P, Christ D, et al. The chemotactic receptor EBI2 regulates the homeostasis, localization and immunological function of splenic dendritic cells. Nat Immunol. 2013;14(8):876.

12. Yi T, Cyster JG. EBI2-mediated bridging channel positioning supports splenic dendritic cell homeostasis and particulate antigen capture. Elife. 2013;2:e00757.

13. Li J, Lu E, Yi T, Cyster JG. EBI2 augments Tfh cell fate by promoting interaction with IL2-quenching dendritic cells. Nature. 2016;533(7601):110-4. 
14. Clottu AS, Mathias A, Sailer AW, Schluep M, Seebach JD, Du Pasquier R, et al. EBI2 Expression and Function: Robust in Memory Lymphocytes and Increased by Natalizumab in Multiple Sclerosis. Cell Rep. 2017;18(1):213-24.

15. Lu E, Cyster JG. G-protein coupled receptors and ligands that organize humoral immune responses. Immunol Rev. 2019;289(1):158-72.

16. Yi T, Wang X, Kelly LM, An J, Xu Y, Sailer AW, et al. Oxysterol gradient generation by lymphoid stromal cells guides activated $B$ cell movement during humoral responses. Immunity. 2012;37(3):535-48.

17. Durai V, Murphy KM. Functions of Murine Dendritic Cells. Immunity. 2016;45(4):71936.

18. Joeris T, Muller-Luda K, Agace WW, Mowat AM. Diversity and functions of intestinal mononuclear phagocytes. Mucosal Immunol. 2017;10(4):845-64.

19. Lu E, Dang EV, McDonald JG, Cyster JG. Distinct oxysterol requirements for positioning naive and activated dendritic cells in the spleen. Sci Immunol. 2017;2(10).

20. Baptista AP, Gola A, Huang Y, Milanez-Almeida P, Torabi-Parizi P, Urban JF, Jr., et al. The Chemoattractant Receptor Ebi2 Drives Intranodal Naive CD4(+) T Cell Peripheralization to Promote Effective Adaptive Immunity. Immunity. 2019;50(5):1188-201 e6.

21. Gatto D, Paus D, Basten A, Mackay CR, Brink R. Guidance of B cells by the orphan $G$ protein-coupled receptor EBI2 shapes humoral immune responses. Immunity.

2009;31(2):259-69.

22. Kelly LM, Pereira JP, Yi T, Xu Y, Cyster JG. EBI2 guides serial movements of activated $B$ cells and ligand activity is detectable in lymphoid and nonlymphoid tissues. J Immunol. 2011;187(6):3026-32.

23. Pereira JP, Kelly LM, Xu Y, Cyster JG. EBI2 mediates B cell segregation between the outer and centre follicle. Nature. 2009;460(7259):1122-6.

24. Vivier E, Artis D, Colonna M, Diefenbach A, Di Santo JP, Eberl G, et al. Innate Lymphoid Cells: 10 Years On. Cell. 2018;174(5):1054-66.

25. Ebbo $M$, Crinier A, Vely F, Vivier E. Innate lymphoid cells: major players in inflammatory diseases. Nat Rev Immunol. 2017;17(11):665-78.

26. Kotas ME, Locksley RM. Why Innate Lymphoid Cells? Immunity. 2018;48(6):1081-90.

27. Panda SK, Colonna M. Innate Lymphoid Cells in Mucosal Immunity. Front Immunol. 2019;10:861.

28. Mjosberg J, Spits H. Human innate lymphoid cells. J Allergy Clin Immunol. 2016;138(5):1265-76.

29. Pantazi E, Powell N. Group 3 ILCs: Peacekeepers or Troublemakers? What's Your Gut Telling You?! Front Immunol. 2019;10:676.

30. Sonnenberg GF, Monticelli LA, Alenghat T, Fung TC, Hutnick NA, Kunisawa J, et al. Innate lymphoid cells promote anatomical containment of lymphoid-resident commensal bacteria. Science. 2012;336(6086):1321-5.

31. Zheng Y, Valdez PA, Danilenko DM, Hu Y, Sa SM, Gong Q, et al. Interleukin-22 mediates early host defense against attaching and effacing bacterial pathogens. Nat Med. 2008;14(3):282-9.

32. Hernandez PP, Mahlakoiv T, Yang I, Schwierzeck V, Nguyen N, Guendel F, et al. Interferon-lambda and interleukin 22 act synergistically for the induction of interferonstimulated genes and control of rotavirus infection. Nat Immunol. 2015;16(7):698-707. 33. Griffiths WJ, Wang Y. An update on oxysterol biochemistry: New discoveries in lipidomics. Biochem Biophys Res Commun. 2018;504(3):617-22. 
34. Kumar D, Nath L, Kamal MA, Varshney A, Jain A, Singh S, et al. Genome-wide analysis of the host intracellular network that regulates survival of Mycobacterium tuberculosis. Cell. 2010;140(5):731-43.

35. Tang J, Shi Y, Zhan L, Qin C. Downregulation of GPR183 on infection restricts the early infection and intracellular replication of mycobacterium tuberculosis in macrophage. Microb Pathog. 2020;145:104234.

36. Huang J, Lee SJ, Kang S, Choi MH, Im DS. 7alpha,25-dihydroxycholesterol protects against liver $X$ receptor-mediated steatosis through GPR183/EBI2 in human and mouse hepatocytes. J Pharmacol Exp Ther. 2020.

37. Buettner M, Lochner M. Development and Function of Secondary and Tertiary Lymphoid Organs in the Small Intestine and the Colon. Front Immunol. 2016;7:342.

38. Randall TD, Carragher DM, Rangel-Moreno J. Development of secondary lymphoid organs. Annu Rev Immunol. 2008;26:627-50.

39. van de Pavert SA, Mebius RE. New insights into the development of lymphoid tissues. Nat Rev Immunol. 2010;10(9):664-74.

40. Eberl G, Littman DR. Thymic origin of intestinal alphabeta T cells revealed by fate mapping of RORgammat+ cells. Science. 2004;305(5681):248-51.

41. Lorenz RG, Chaplin DD, McDonald KG, McDonough JS, Newberry RD. Isolated lymphoid follicle formation is inducible and dependent upon lymphotoxin-sufficient $B$ lymphocytes, lymphotoxin beta receptor, and TNF receptor I function. J Immunol. 2003;170(11):5475-82.

42. Bouskra D, Brezillon C, Berard M, Werts C, Varona R, Boneca IG, et al. Lymphoid tissue genesis induced by commensals through NOD1 regulates intestinal homeostasis. Nature. 2008;456(7221):507-10.

43. Pabst $\mathrm{O}$, Herbrand $\mathrm{H}$, Friedrichsen $\mathrm{M}$, Velaga S, Dorsch $\mathrm{M}$, Berhardt $\mathrm{G}$, et al. Adaptation of solitary intestinal lymphoid tissue in response to microbiota and chemokine receptor CCR7 signaling. J Immunol. 2006;177(10):6824-32.

44. Fenton TM, Jorgensen PB, Niss K, Rubin SJS, Morbe UM, Riis LB, et al. Immune Profiling of Human Gut-Associated Lymphoid Tissue Identifies a Role for Isolated Lymphoid Follicles in Priming of Region-Specific Immunity. Immunity. 2020;52(3):557-70 e6.

45. Tsuji M, Suzuki K, Kitamura H, Maruya M, Kinoshita K, Ivanov, II, et al. Requirement for lymphoid tissue-inducer cells in isolated follicle formation and T cell-independent immunoglobulin A generation in the gut. Immunity. 2008;29(2):261-71.

46. Vedamurthy A, Ananthakrishnan AN. Influence of Environmental Factors in the Development and Outcomes of Inflammatory Bowel Disease. Gastroenterology \& hepatology. 2019;15(2):72-82.

47. Annese V. Genetics and epigenetics of IBD. Pharmacol Res. 2020;159:104892.

48. Jostins L, Ripke S, Weersma RK, Duerr RH, McGovern DP, Hui KY, et al. Host-microbe interactions have shaped the genetic architecture of inflammatory bowel disease. Nature. 2012;491(7422):119-24.

49. de Lange KM, Moutsianas L, Lee JC, Lamb CA, Luo Y, Kennedy NA, et al. Genomewide association study implicates immune activation of multiple integrin genes in inflammatory bowel disease. Nat Genet. 2017;49(2):256-61.

50. Franke A, McGovern DP, Barrett JC, Wang K, Radford-Smith GL, Ahmad T, et al. Genome-wide meta-analysis increases to 71 the number of confirmed Crohn's disease susceptibility loci. Nat Genet. 2010;42(12):1118-25.

This article is protected by copyright. All rights reserved. 
51. McGovern DP, Gardet A, Torkvist L, Goyette P, Essers J, Taylor KD, et al. Genomewide association identifies multiple ulcerative colitis susceptibility loci. Nat Genet. 2010;42(4):332-7.

52. Sawalha AH, Hughes T, Nadig A, Yilmaz V, Aksu K, Keser G, et al. A putative functional variant within the UBAC2 gene is associated with increased risk of Behcet's disease. Arthritis Rheum. 2011;63(11):3607-12.

53. Hou S, Shu Q, Jiang Z, Chen Y, Li F, Chen F, et al. Replication study confirms the association between UBAC2 and Behcet's disease in two independent Chinese sets of patients and controls. Arthritis Res Ther. 2012;14(2):R70.

54. Yamazoe K, Meguro A, Takeuchi M, Shibuya E, Ohno S, Mizuki N. Comprehensive analysis of the association between UBAC2 polymorphisms and Behcet's disease in a Japanese population. Sci Rep. 2017;7(1):742.

55. Yurdakul S, Hamuryudan V, Yazici H. Behcet syndrome. Curr Opin Rheumatol. 2004;16(1):38-42.

56. Valenti S, Gallizzi R, De Vivo D, Romano C. Intestinal Behcet and Crohn's disease: two sides of the same coin. Pediatr Rheumatol Online J. 2017;15(1):33.

57. Cheon JH, Kim WH. An update on the diagnosis, treatment, and prognosis of intestinal Behcet's disease. Curr Opin Rheumatol. 2015;27(1):24-31.

58. Takeuchi M, Mizuki N, Meguro A, Ombrello MJ, Kirino Y, Satorius C, et al. Dense genotyping of immune-related loci implicates host responses to microbial exposure in Behcet's disease susceptibility. Nat Genet. 2017;49(3):438-43.

59. Choi JH, Zhong X, McAlpine W, Liao TC, Zhang D, Fang B, et al. LMBR1L regulates lymphopoiesis through Wnt/beta-catenin signaling. Science. 2019;364(6440).

60. Olzmann JA, Richter CM, Kopito RR. Spatial regulation of UBXD8 and p97/VCP controls ATGL-mediated lipid droplet turnover. Proc Natl Acad Sci U S A. 2013;110(4):134550.

61. Fei Y, Webb R, Cobb BL, Direskeneli H, Saruhan-Direskeneli G, Sawalha AH. Identification of novel genetic susceptibility loci for Behcet's disease using a genome-wide association study. Arthritis Res Ther. 2009;11(3):R66.

62. Di Narzo AF, Peters LA, Argmann C, Stojmirovic A, Perrigoue J, Li K, et al. Blood and Intestine eQTLs from an Anti-TNF-Resistant Crohn's Disease Cohort Inform IBD Genetic Association Loci. Clin Transl Gastroenterol. 2016;7(6):e177.

63. Burke KE, Khalili H, Garber JJ, Haritunians T, McGovern DPB, Xavier RJ, et al. Genetic Markers Predict Primary Nonresponse and Durable Response to Anti-Tumor Necrosis Factor Therapy in Ulcerative Colitis. Inflamm Bowel Dis. 2018;24(8):1840-8.

64. Kotlarz D, Beier R, Murugan D, Diestelhorst J, Jensen O, Boztug K, et al. Loss of interleukin-10 signaling and infantile inflammatory bowel disease: implications for diagnosis and therapy. Gastroenterology. 2012;143(2):347-55.

65. Schaubeck M, Clavel T, Calasan J, Lagkouvardos I, Haange SB, Jehmlich N, et al. Dysbiotic gut microbiota causes transmissible Crohn's disease-like ileitis independent of failure in antimicrobial defence. Gut. 2016;65(2):225-37.

66. Tedde A, Laura Putignano A, Bagnoli S, Congregati C, Milla M, Sorbi S, et al. Interleukin-10 promoter polymorphisms influence susceptibility to ulcerative colitis in a gender-specific manner. Scand J Gastroenterol. 2008;43(6):712-8.

67. Wauthier V, Sugathan A, Meyer RD, Dombkowski AA, Waxman DJ. Intrinsic sex differences in the early growth hormone responsiveness of sex-specific genes in mouse liver. Mol Endocrinol. 2010;24(3):667-78.

This article is protected by copyright. All rights reserved. 
68. Preuss I, Ludwig MG, Baumgarten B, Bassilana F, Gessier F, Seuwen K, et al. Transcriptional regulation and functional characterization of the oxysterol/EBI2 system in primary human macrophages. Biochem Biophys Res Commun. 2014;446(3):663-8. 69. Schroder K, Irvine KM, Taylor MS, Bokil NJ, Le Cao KA, Masterman KA, et al. Conservation and divergence in Toll-like receptor 4-regulated gene expression in primary human versus mouse macrophages. Proc Natl Acad Sci U S A. 2012;109(16):E944-53.

70. Lattin JE, Schroder K, Su Al, Walker JR, Zhang J, Wiltshire T, et al. Expression analysis of $\mathrm{G}$ Protein-Coupled Receptors in mouse macrophages. Immunome Res. 2008;4:5.

71. Raselli T, Wyss A, Gonzalez Alvarado MN, Weder B, Mamie C, Spalinger MR, et al. The Oxysterol Synthesising Enzyme $\mathrm{CH} 25 \mathrm{H}$ Contributes to the Development of Intestinal Fibrosis. J Crohns Colitis. 2019;13(9):1186-200.

72. Guillemot-Legris $O$, Mutemberezi V, Buisseret B, Paquot A, Palmieri V, Bottemanne $P$, et al. Colitis Alters Oxysterol Metabolism and is Affected by 4 beta-Hydroxycholesterol Administration. J Crohns Colitis. 2019;13(2):218-29.

73. Wu J, McDuffie JE, Song J, Harris MC, Raymond H, Chen Y, et al. LC/MS/MS Profiling of Tissue Oxysterols and its Application in Dextran Sodium Sulphate Induced Mouse Colitis Models. Curr Top Med Chem. 2017;17(24):2781-90.

74. Raselli T, Hearn T, Wyss A, Atrott K, Peter A, Frey-Wagner I, et al. Elevated oxysterol levels in human and mouse livers reflect nonalcoholic steatohepatitis. J Lipid Res. 2019;60(7):1270-83.

75. Willinger T. Oxysterols in intestinal immunity and inflammation. J Intern Med. 2019;285(4):367-80.

76. Bauman DR, Bitmansour AD, McDonald JG, Thompson BM, Liang G, Russell DW. 25Hydroxycholesterol secreted by macrophages in response to Toll-like receptor activation suppresses immunoglobulin A production. Proc Natl Acad Sci U S A. 2009;106(39):16764-9. 77. Diczfalusy U, Olofsson KE, Carlsson AM, Gong M, Golenbock DT, Rooyackers O, et al. Marked upregulation of cholesterol 25-hydroxylase expression by lipopolysaccharide. J Lipid Res. 2009;50(11):2258-64.

78. Blanc M, Hsieh WY, Robertson KA, Kropp KA, Forster T, Shui G, et al. The transcription factor STAT-1 couples macrophage synthesis of 25-hydroxycholesterol to the interferon antiviral response. Immunity. 2013;38(1):106-18.

79. Liu SY, Aliyari R, Chikere K, Li G, Marsden MD, Smith JK, et al. Interferon-inducible cholesterol-25-hydroxylase broadly inhibits viral entry by production of 25-

hydroxycholesterol. Immunity. 2013;38(1):92-105.

80. Park K, Scott AL. Cholesterol 25-hydroxylase production by dendritic cells and macrophages is regulated by type I interferons. J Leukoc Biol. 2010;88(6):1081-7.

81. Abrams ME, Johnson KA, Perelman SS, Zhang LS, Endapally S, Mar KB, et al. Oxysterols provide innate immunity to bacterial infection by mobilizing cell surface accessible cholesterol. Nat Microbiol. 2020.

82. Reboldi A, Dang EV, McDonald JG, Liang G, Russell DW, Cyster JG. Inflammation. 25Hydroxycholesterol suppresses interleukin-1-driven inflammation downstream of type I interferon. Science. 2014;345(6197):679-84.

83. Mufazalov IA, Schelmbauer C, Regen T, Kuschmann J, Wanke F, Gabriel LA, et al. IL-1 signaling is critical for expansion but not generation of autoreactive GM-CSF+ Th17 cells. EMBO J. 2017;36(1):102-15. 
84. Jakobsson T, Treuter E, Gustafsson JA, Steffensen KR. Liver X receptor biology and pharmacology: new pathways, challenges and opportunities. Trends Pharmacol Sci. 2012;33(7):394-404.

85. Jakobsson T, Vedin LL, Hassan T, Venteclef N, Greco D, D'Amato M, et al. The oxysterol receptor LXRbeta protects against DSS- and TNBS-induced colitis in mice. Mucosal Immunol. 2014;7(6):1416-28.

86. Soroosh P, Wu J, Xue X, Song J, Sutton SW, Sablad M, et al. Oxysterols are agonist ligands of RORgammat and drive Th17 cell differentiation. Proc Natl Acad Sci U S A. 2014;111(33):12163-8.

87. Ueno A, Jeffery L, Kobayashi T, Hibi T, Ghosh S, Jijon H. Th17 plasticity and its relevance to inflammatory bowel disease. J Autoimmun. 2018;87:38-49.

88. Lochner M, Ohnmacht C, Presley L, Bruhns P, Si-Tahar M, Sawa S, et al. Microbiotainduced tertiary lymphoid tissues aggravate inflammatory disease in the absence of RORgamma t and LTi cells. J Exp Med. 2011;208(1):125-34.

89. Drayton DL, Ying X, Lee J, Lesslauer W, Ruddle NH. Ectopic LT alpha beta directs lymphoid organ neogenesis with concomitant expression of peripheral node addressin and a HEV-restricted sulfotransferase. J Exp Med. 2003;197(9):1153-63.

90. Pearson C, Thornton EE, McKenzie B, Schaupp AL, Huskens N, Griseri T, et al. ILC3 GM-CSF production and mobilisation orchestrate acute intestinal inflammation. Elife. 2016;5:e10066.

91. McNamee EN, Rivera-Nieves J. Ectopic Tertiary Lymphoid Tissue in Inflammatory Bowel Disease: Protective or Provocateur? Front Immunol. 2016;7:308.

92. Ota N, Wong K, Valdez PA, Zheng Y, Crellin NK, DiehI L, et al. IL-22 bridges the lymphotoxin pathway with the maintenance of colonic lymphoid structures during infection with Citrobacter rodentium. Nat Immunol. 2011;12(10):941-8.

93. McNamee EN, Masterson JC, Jedlicka P, Collins CB, Williams IR, Rivera-Nieves J.

Ectopic lymphoid tissue alters the chemokine gradient, increases lymphocyte retention and exacerbates murine ileitis. Gut. 2013;62(1):53-62.

94. Spahn TW, Herbst H, Rennert PD, Lugering N, Maaser C, Kraft M, et al. Induction of colitis in mice deficient of Peyer's patches and mesenteric lymph nodes is associated with increased disease severity and formation of colonic lymphoid patches. Am J Pathol.

2002;161(6):2273-82.

95. Sura R, Colombel JF, Van Kruiningen HJ. Lymphatics, tertiary lymphoid organs and the granulomas of Crohn's disease: an immunohistochemical study. Aliment Pharmacol Ther. 2011;33(8):930-9.

96. Cui Y, Lu SY, Xu J, Peng YS, Miao Q, Wang XQ, et al. Microscopic features of small bowel mucosa of patients with Crohn's disease. BMC Gastroenterol. 2019;19(1):232.

97. Marchesi F, Martin AP, Thirunarayanan N, Devany E, Mayer L, Grisotto MG, et al. CXCL13 expression in the gut promotes accumulation of IL-22-producing lymphoid tissueinducer cells, and formation of isolated lymphoid follicles. Mucosal Immunol. 2009;2(6):48694.

98. Sandborn WJ, Colombel JF, Enns R, Feagan BG, Hanauer SB, Lawrance IC, et al. Natalizumab induction and maintenance therapy for Crohn's disease. N Engl J Med. 2005;353(18):1912-25.

99. Sandborn WJ, Feagan BG, Rutgeerts P, Hanauer S, Colombel JF, Sands BE, et al. Vedolizumab as induction and maintenance therapy for Crohn's disease. N Engl J Med. 2013;369(8):711-21.

This article is protected by copyright. All rights reserved. 
100. Feagan BG, Rutgeerts P, Sands BE, Hanauer S, Colombel JF, Sandborn WJ, et al. Vedolizumab as induction and maintenance therapy for ulcerative colitis. $\mathrm{N}$ Engl J Med. 2013;369(8):699-710.

101. Krupka N, Baumgart DC. Designing biologic selectivity for inflammatory bowel disease--role of vedolizumab. Drug design, development and therapy. 2015;9:147-54. 102. Bohra C, Sokol L, Dalia S. Progressive Multifocal Leukoencephalopathy and Monoclonal Antibodies: A Review. Cancer Control. 2017;24(4):1073274817729901. 103. Vermeire S, Colombel J, Feagan B, Sandborn W, Sands B, Danese S, et al. Long-term safety of vedolizumab in ulcerative colitis and Crohn's disease: final results from the GEMINI LTS study Journal of Crohn's and Colitis. 2019;ECCO oral presentation OP26.

104. Duc D, Vigne S, Pot C. Oxysterols in Autoimmunity. Int J Mol Sci. 2019;20(18).

105. Stepanovska B, Huwiler A. Targeting the S1P receptor signaling pathways as a promising approach for treatment of autoimmune and inflammatory diseases. Pharmacol Res. 2019.

106. Sandborn WJ, Feagan BG, Wolf DC, D'Haens G, Vermeire S, Hanauer SB, et al. Ozanimod Induction and Maintenance Treatment for Ulcerative Colitis. N Engl J Med. 2016;374(18):1754-62.

107. Peyrin-Biroulet L, Christopher R, Behan D, Lassen C. Modulation of sphingosine-1phosphate in inflammatory bowel disease. Autoimmun Rev. 2017;16(5):495-503.

108. Feagan BG, Sandborn WJ, D'Haens G, Lee SD, Allez M, Fedorak RN, et al. Randomised clinical trial: vercirnon, an oral CCR9 antagonist, vs. placebo as induction therapy in active Crohn's disease. Aliment Pharmacol Ther. 2015;42(10):1170-81.

109. Biswas S, Bryant RV, Travis S. Interfering with leukocyte trafficking in Crohn's disease. Best Pract Res Clin Gastroenterol. 2019;38-39:101617.

110. Perez-Jeldres T, Tyler CJ, Boyer JD, Karuppuchamy T, Bamias G, Dulai PS, et al. Cell Trafficking Interference in Inflammatory Bowel Disease: Therapeutic Interventions Based on Basic Pathogenesis Concepts. Inflamm Bowel Dis. 2019;25(2):270-82.

111. Trivedi PJ, Adams DH. Chemokines and Chemokine Receptors as Therapeutic Targets in Inflammatory Bowel Disease; Pitfalls and Promise. J Crohns Colitis. 2018;12(12):1508.

112. Mayer L, Sandborn WJ, Stepanov Y, Geboes K, Hardi R, Yellin M, et al. Anti-IP-10 antibody (BMS-936557) for ulcerative colitis: a phase II randomised study. Gut.

2014;63(3):442-50.

113. Gessier F, Preuss I, Yin H, Rosenkilde MM, Laurent S, Endres R, et al. Identification and characterization of small molecule modulators of the Epstein-Barr virus-induced gene 2 (EBI2) receptor. J Med Chem. 2014;57(8):3358-68.

114. Braden K, Giancotti LA, Chen Z, DeLeon C, Latzo N, Boehm T, et al. GPR183-oxysterol axis in spinal cord contributes to neuropathic pain. J Pharmacol Exp Ther. 2020.

115. Harding SD, Sharman JL, Faccenda E, Southan C, Pawson AJ, Ireland S, et al. The IUPHAR/BPS Guide to PHARMACOLOGY in 2018: updates and expansion to encompass the new guide to IMMUNOPHARMACOLOGY. Nucleic acids research. 2018;46(D1):D1091-D106. 


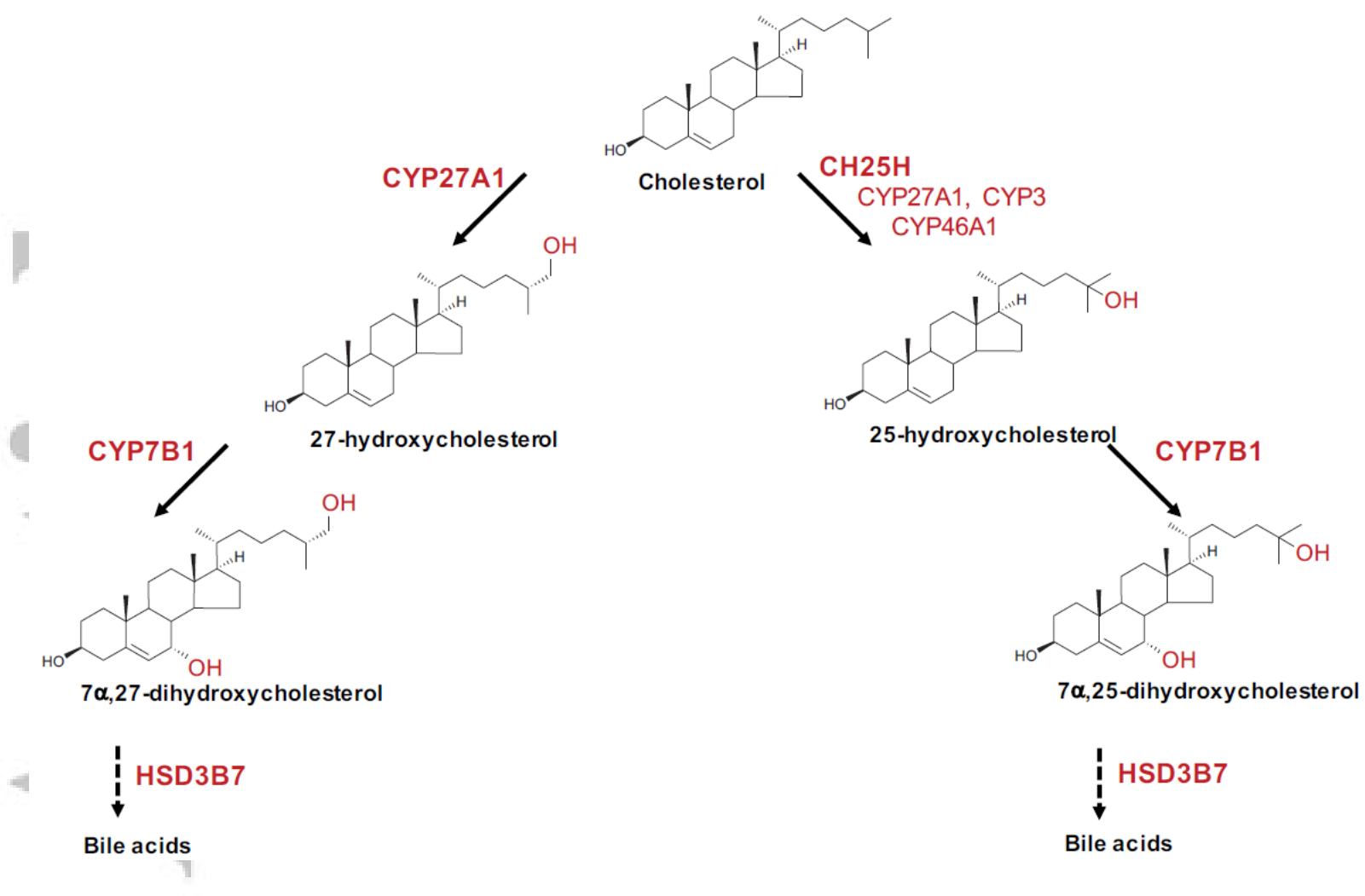

Figure 1: Biosynthesis and degradation of oxysterols.

Oxysterol biosynthesis starts with oxidation at the 25-position by the enzyme cholesterol 25hydroxylase $(\mathrm{CH} 25 \mathrm{H})$ or at the 27 -position by cytochrome p450 family 27 member A1 (CYP27A1), yielding 25-hydroxycholesterol (25-HC) and 27-hydroxycholesterol (27-HC), respectively. Further $7 \alpha-$ hydroxylation by CYP7B1 results in production of $7 \alpha, 25$-diHC and $7 \alpha, 27-d i H C$, respectively. Oxysterols are ultimately degraded to bile acids by the activity of hydroxy-delta-5-steroid dehydrogenase, 3 beta- and steroid delta-isomerase 7 (HSD3B7). 


\section{7 $\alpha, 25$-diHC concentration}

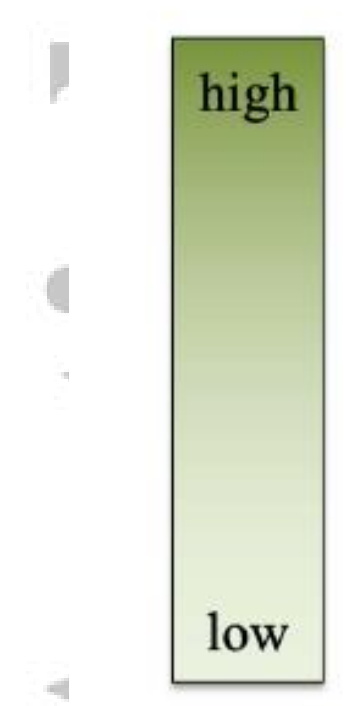

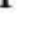
channel

- $B$ cells expressing GPR183

- B cells expressing GPR183 and CCR7
Bridging

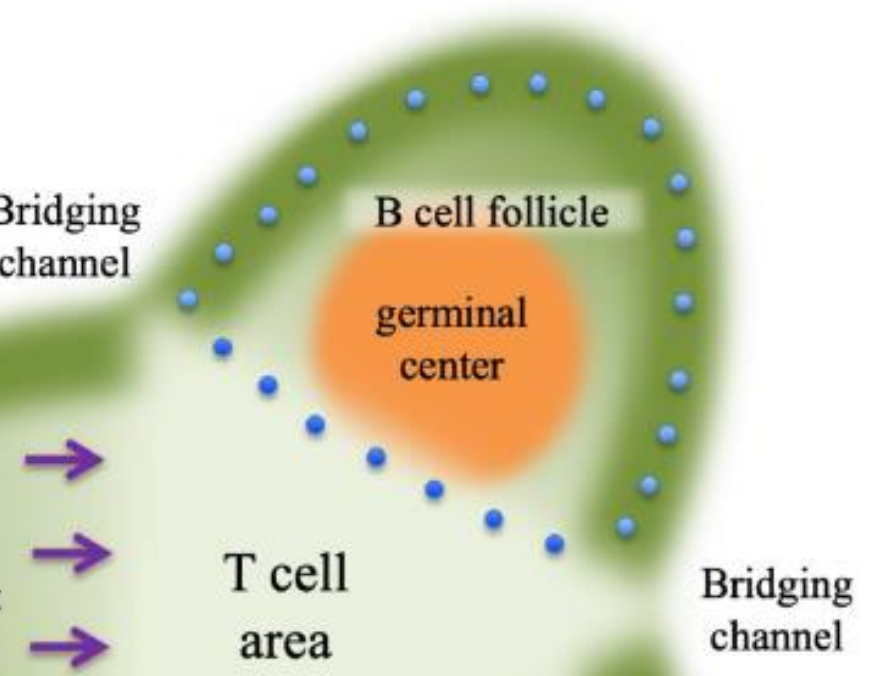

\section{GPR183}

dependent migration

Bridging channel
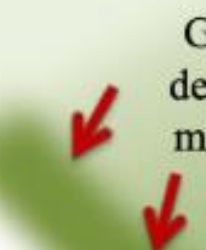
channel

\section{Figure 2: GPR183 dependent movements of immune cells in secondary lymphoid organs}

B cell follicles with germinal centre (orange) and the T cell area are indicated. A gradient of the GPR183 ligand $7 \alpha, 25$-diHC is expected in secondary lymphoid organs according to expression levels of the

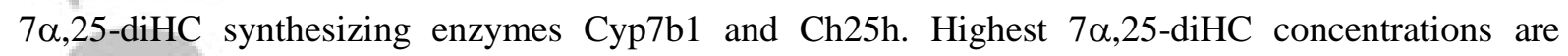
expected in the outer follicle (dark green). GPR183 expressing B cells, T cells and dendritic cells follow the 7 $\alpha, 25$-diHC gradient (red arrows) and some B cells move to the outer follicle (light blue circle). For other immune cells with concurrent expression of other chemokine receptors (e.g. CCR7, purple arrows) positioning reflects the effects of more than one cytokine and B cells are also found in the interfollicular area (dark blue circles). GPR183 also supports positioning of T cells and DCs (not indicated). 

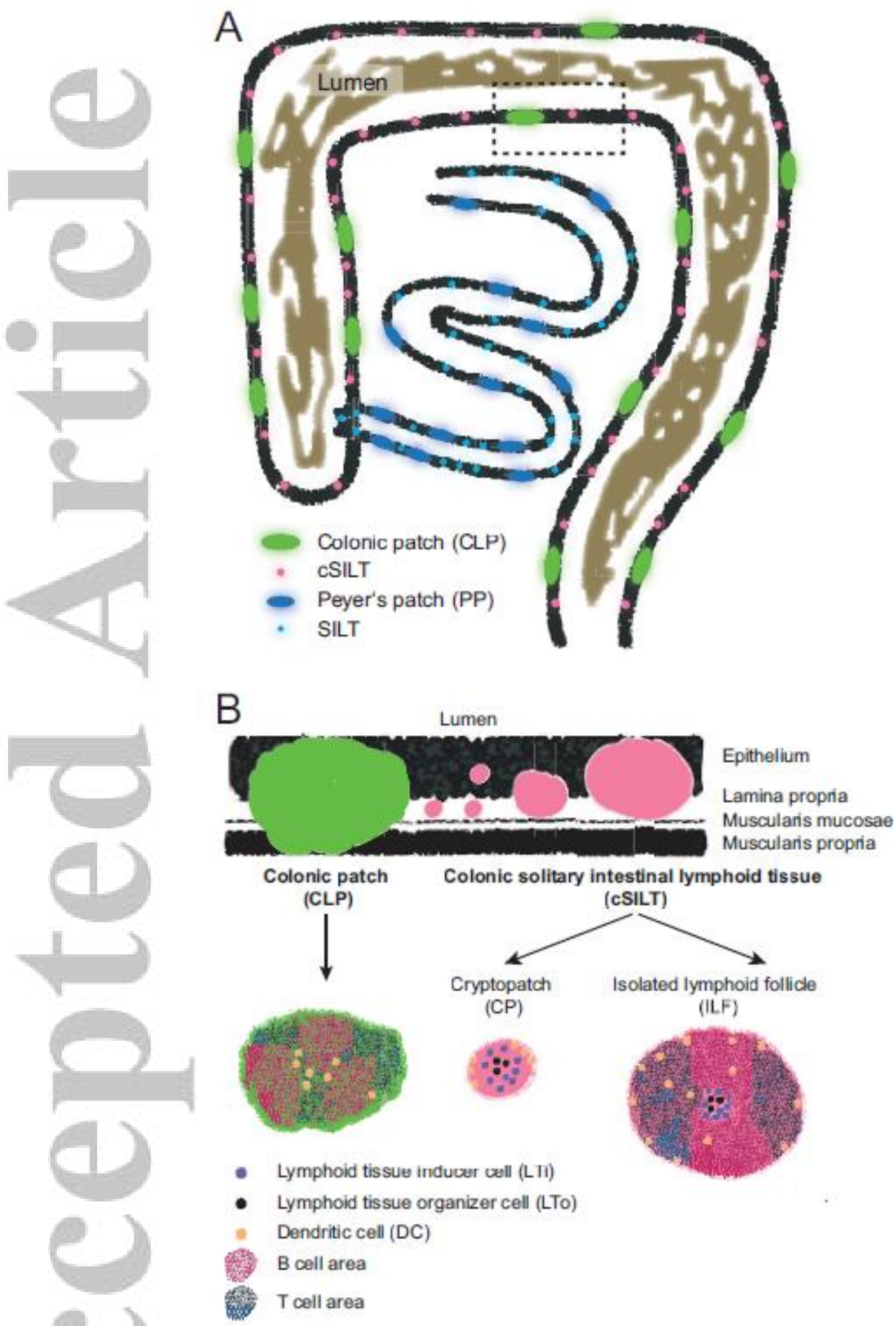

Figure 3: Schematic view of lymphoid structures in the colon and the small intestine.

(A) Overview of the small intestine and the colon with intramucosal solitary intestinal lymphoid tissue (SILT) and colonic SILT (cSILT) as well as larger mucosal and submucosal Peyer's patches and colonic patches (CLP)

(B) Schematic view of location of lymphoid structures and its cellular content. Please note the strict intramucosal of cSILT comprising small cryptopatches and larger isolated lymphoid tissue 


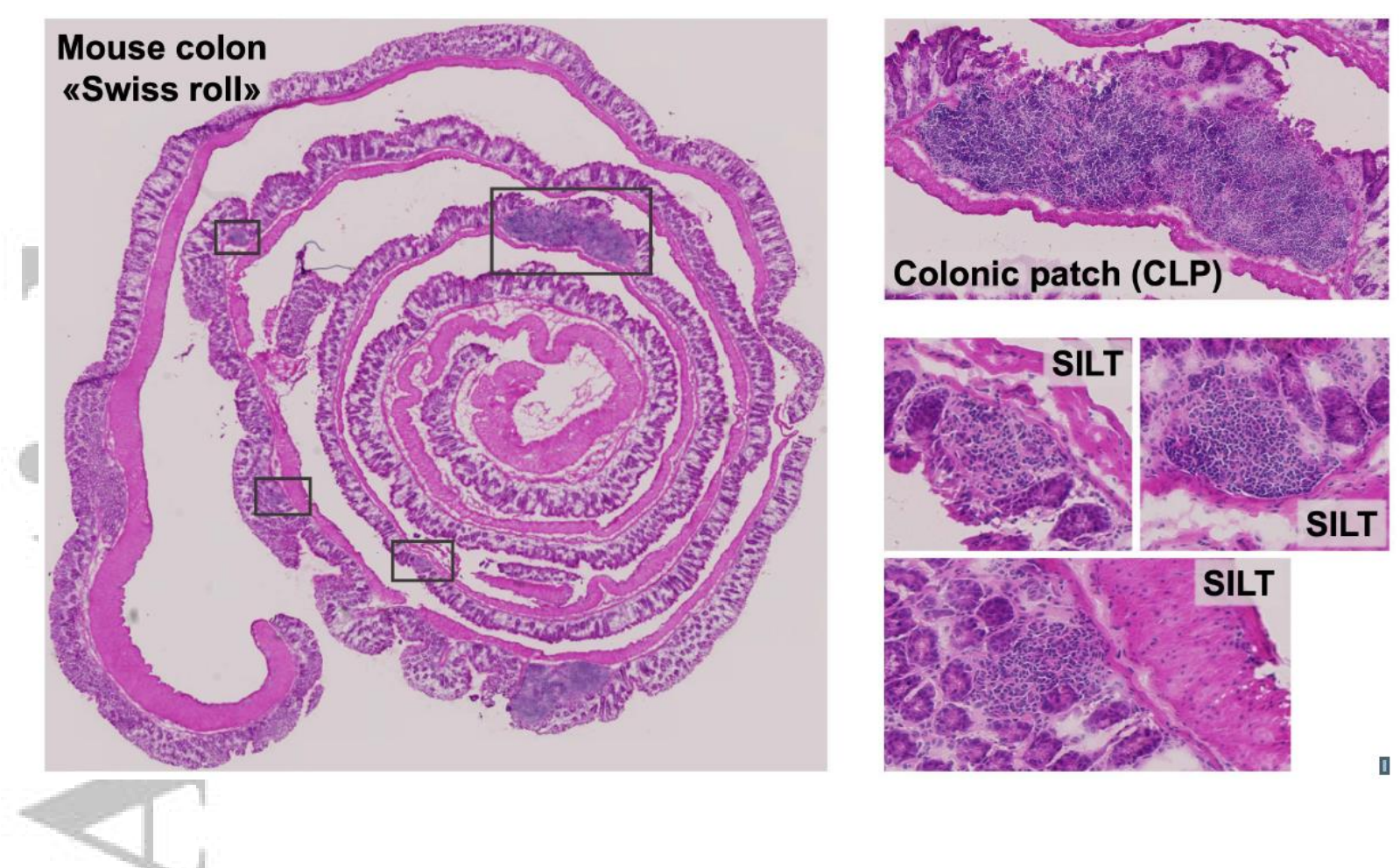

Figure 4: Key structures of the colonic immune system.

Left panel: complete mouse colon as a "Swiss roll". Inserts indicate colonic patches (CLP) and solitary intestinal lymphoid tissue (SILT), shown on the right. While CLPs replace mucosa and submucosa, SILTs are strict mucosal structures, respecting the tunica muscularis mucosae (arrows). Cryptopatches are small SILTs comprising mainly lymphoid tissue inducer (LTi) cells and dendritic cells (DCs) but lack B cells (not shown). Acquisition of B cells yields larger SILTs, called intestinal lymphoid follicles (ILF). 


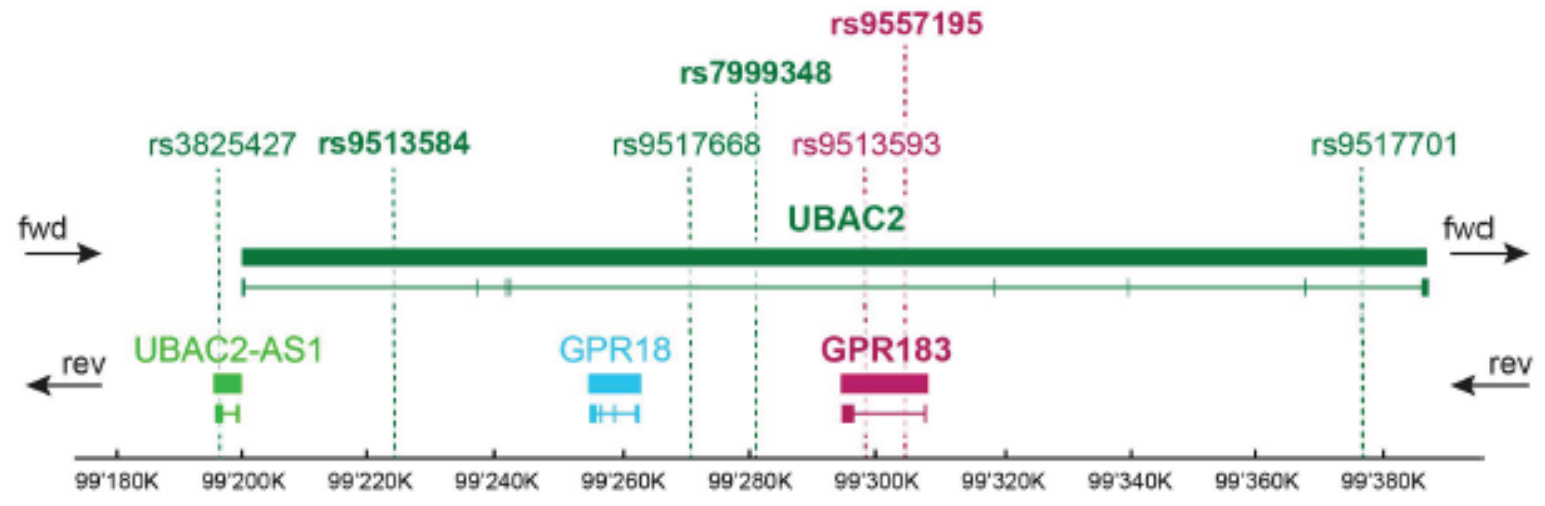

Figure 5: Architecture of the GPR183/ UBAC2 gene locus on chromosome 13

The UBAC2 gene (green) is located on the forward (fwd) strand of chromosome 13, while the GPR183 gene (pink) is located on the reverse (rev) strand. Neighbouring genes encoding G-protein coupled receptor 18 (GPR18) and UBAC2 antisense RNA 1 (UBAC2-AS1) are also indicated. The major transcript of the respective genes with its introns (horizontal line) and exons (rectangles or vertical lines) are indicated in grey. Relevant SNPs (for instance the IBD-SNP rs9557195, the psoriasis-SNP rs9513593 or the Behçet's disease-SNPs rs3825427, rs799348) are highlighted with the colour of the associated gene. 
Table 1: Cellular targets of oxysterols and downstream effects.

\begin{tabular}{|c|c|c|c|}
\hline Oxysterol ligand & Cellular target & $\begin{array}{l}\text { Exemplary downstream effects and } \\
\text { effects in the intestine (if } \\
\text { applicable). }\end{array}$ & Reference \\
\hline $\begin{array}{l}7 \beta, 27-\mathrm{diHC} \\
7 \alpha, 27-\mathrm{diHC}\end{array}$ & $\mathrm{ROR} \gamma \mathrm{t} \uparrow$ & $\begin{array}{l}\text { Th17, ILC3 differentiation, induction } \\
\text { of SILTs in the colon }\end{array}$ & $\begin{array}{l}(3,38-42, \\
73)\end{array}$ \\
\hline \multirow[t]{2}{*}{ 25-HC, 27-HC } & LXR- $\alpha$, LXR- $\beta \uparrow$ & $\begin{array}{l}\text { Anti-inflammatory effects in colitis, } \\
\text { cellular metabolism and immunity }\end{array}$ & $\begin{array}{l}(71,72, \\
109)\end{array}$ \\
\hline & INSIG $\uparrow$, SREBP $\downarrow$ & $\begin{array}{l}\text { Inhibition of cholesterol synthesis, } \\
\text { effects in the intestine unclear }\end{array}$ & $(110)$ \\
\hline \multirow[t]{3}{*}{$25-\mathrm{HC}$} & Inflammasome $\downarrow$ & $\begin{array}{l}\text { Inflammasome inhibition, reduced } \\
\text { production of IL-1 and IL-18 }\end{array}$ & (69) \\
\hline & Antibacterial defence $\uparrow$ & $\begin{array}{l}\text { Reduction of accessible membrane } \\
\text { cholesterol. Inhibits replication of } L \text {. } \\
\text { monocytogenes, S. flexneri }\end{array}$ & (68) \\
\hline & Antiviral defence $\uparrow$ & $\begin{array}{l}\text { Inhibits replication of a number of } \\
\text { viruses }\end{array}$ & $(65,66)$ \\
\hline 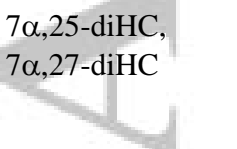 & GPR183 & $\begin{array}{l}\text { Positioning of B cells, T cells, DCs, } \\
\text { ILC3s. Formation of SILTs in the } \\
\text { colon, pro-inflammatory effects in } \\
\text { colitis (see text for details). }\end{array}$ & $\begin{array}{l}(2,3,5,8 \\
9,26-28 \\
34)\end{array}$ \\
\hline
\end{tabular}

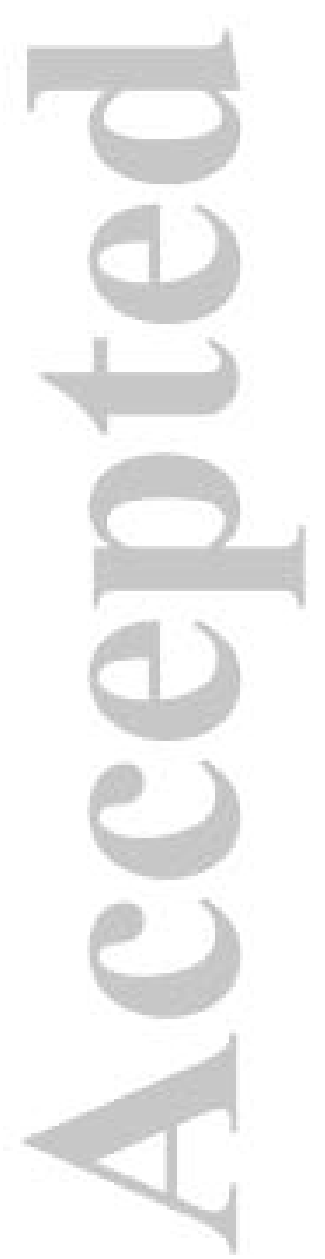

